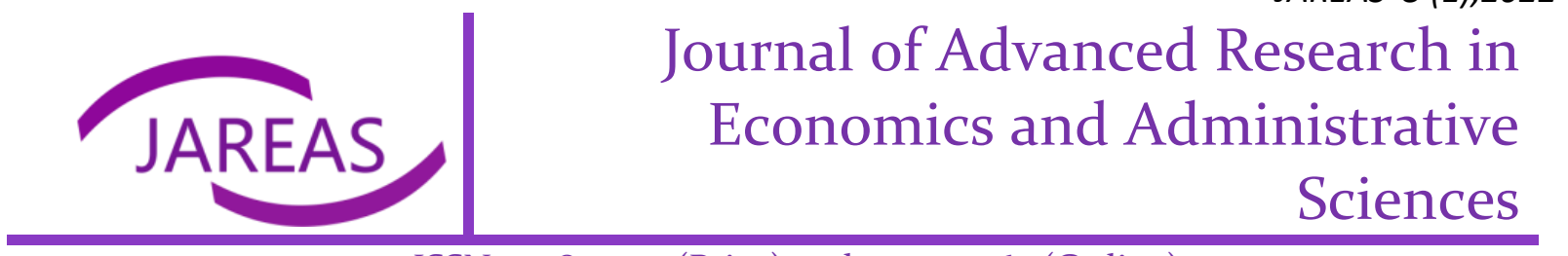

ISSN 2708-9320 (Print) and 2709-0965 (Online)

\title{
HUMAN RESOURCE MANAGEMENT CHALLENGES AMIDST COVID-19 PANDEMIC: BEHAVIORAL IMPLICATIONS FOR HR PRACTITIONERS
}

\author{
Nishath Anjum (iD, Md. Saidur Rahaman iD \\ ${ }^{1}$ Assistant Professor, Department of Business Administration, Metropolitan University, Sylhet, Bangladesh \\ ${ }^{2}$ Assistant Professor, Department of Business Administration, Metropolitan University, Sylhet, Bangladesh
}

\section{ARTICLE INFO}

Received: 25 December 2021 Revised: 15 February 2022 Accepted: 18 February 2022

Keywords: Human Resource Management, COVID-19 Pandemic, HR Practitioners

Corresponding Author: Nishath Anjum

Email: nishath@metrouni.edu.bd Copyright $@ 2021$ by author(s)

This work is licensed under the Creative Commons Attribution International License (CC BY 4.0). http://creativecommons.org/licenses/ by/4.0/
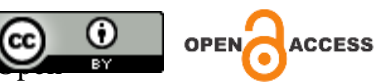

\begin{abstract}
Purpose: This study aims to examine the new challenges for human resource management amidst the COVID-19 pandemic with implications for HR professionals in dealing with their employees.

Approach/Methodology: The study is a general review that attempts to explore the impact of COVID-19 on human resource management. Between December 2019 and July 2021, the researchers did a manual search for the papers that have been published in Scopus, Google Scholar, JSTOR, and Semantic Scholar databases along with many websites. The researcher included the articles based on the scope, area, and variable, where biomedical and epidemiological research has been excluded.

Findings: HR management is facing some invisible challenges that are not new, but during COVID-19, these were multiplied and reached the peaks. Employee health, safety, and mental well-being; employee maintenance, engagement, and flexibility; employee skill and talent management and motivation are the most common challenges.

Practical Implications: The importance of this study lies in its implications on organizations to develop appropriate behavioral strategies to adapt the human resources to the new reality. HR practitioners can use the findings of this study to create effective interventions for dealing with their human resources in any uncertain situation like COVID-19.

Originality/Value: The study presents multiple perspectives on the recent challenges that HR encounters. It is related to the behavioral implications of employees' mental well-being and motivation for the HR professionals of the organizations.
\end{abstract}

\section{INTRODUCTION}

The COVID-19 pandemic has had a major impact on human resource management within organizations, resulting in unprecedented shifts in the business landscape. The digital transformation, remote working system, and COVID-19 associated measures have shifted the traditional HRM and brought many new challenges for human resource management. It has left organizations with uncertainty, volatility, and ambiguity (Nangia \& Mohsin, 2020). The pandemic also imposed many challenges for organizations, including remote working culture, 
performance management, low employee motivation as well as business sustainability (Singh et al., 2021; Yoosefi Lebni et al., 2021). Organizations worldwide are making various adjustments regarding work practices and employee management. As human resource management is critical for sustaining organizational operations, ensuring effective performance and employee well-being is of utmost priority in the current crisis (Risley, 2020; Davidescu et al., 2020). Both the employers and the employees need to adjust to the unexpected alteration to their lives and workplace (Rahaman et al. 2021). The HR professional, in this regard, has a crucial role to play as they are well connected with both the employees and the management.

HR professionals are responsible for managing human resources during this crisis as HRM policies and practices can directly influence employee behavior and performance (Gigauri, 2020, Anjum \& Islam, 2020). The COVID-19 pandemic has created demanding conditions for human resource management (Al-ahdal et al. 2020). Therefore, HR has to revise its previous policies in the context of COVID-19 new norms. Amidst the pandemic, HR managers are encountering challenges specifically in employee maintenance and engagement, employee health and well-being, boosting morale, restoring productivity and motivation, skill management, etc. (Ghewari et al., 2021; Roy, 2021). Human resource managers, along with their regular functions, are also looking for innovative and effective ways to solve employee problems and provide them with additional support to cope with the current scenario (Nisha Chanana, 2020; De Leon, 2020).

Currently, employees' mental health and well-being are becoming a significant concern because of less socialization, job insecurity, virus infection, and uncertainty worldwide (Singer-Velush et al., 2020). HR managers should focus on ensuring employee safety and managing their anxiety, depression, or level of stress. Furthermore, managing a distributed workforce is also very tough (Gigauri, 2020); monitoring and controlling employee activities is far more complex in remote working. In this regard, managers need to use various digital tools for assessing employee performances (Narayandas et al., 2020). Employees also need to learn using technological tools and update their digital skills (Parry and Battista, 2019), which contributes to their employability and sustain their careers in the long run (Sheppard, 2020). When ensuring higher flexibility or using hybrid work amidst this pandemic, employee productivity, job satisfaction, engagement, and private life balance should also be considered significant concerns (Van der Lippe and Lippényi, 2019; Rahman et al., 2020, 2019; Peasley et al., 2020).

Therefore, HRM is facing some critical challenges amidst the COVID-19 pandemic in the case of employee management and engagement. HR practitioners are taking the lead to help organizations navigate the uncertainties considering the challenges of their human resources. They are playing the dominant role in the transportation phase caused by the COVID-19 crisis (Rahaman et al., 2021). This comprehensive review study attempts to identify the core challenges of human resource management amidst the COVID-19 pandemic. It will help the HR practitioners look closely at the critical issues of human resource management during this pandemic and thus, take appropriate strategies or decisions to address the challenges systematically. Finally, the study has practical implications for HR leaders in dealing with the current employee management issues to ensure business continuity, sustain the competition, and improve organizational performances. 


\section{METHODOLOGY AND PROCEDURES}

The study is a general review that attempts to examine the impact of COVID-19 on human resource management and its implications for HR professionals. It has been observed that just a small amount of research has been conducted on this essential phenomenon, which is surprising. As a result, researchers follow a straightforward procedure when writing the paper. Researchers first addressed the problem (HRM challenges during COVID-19), then searched for COVID-19 and human resource management-related papers using the keywords human resource management; HRM; HRM Practices, manpower management, pandemic, HRM challenges, and COVID-19. Finally, researchers were looking for specific papers that addressed the pandemic's impact on contemporary HR management challenges (employee health, safety, and mental well-being; employee maintenance, engagement, and flexibility; employee skill and talent management; and employee productivity and motivation). After that, the researchers write down their observations and critically examine \& summarize the information. Finally, the paper presented a logical argument relevant to the specific occurrence under consideration. Between December 2019 and July 202, in Scopus, Google Scholar, JSTOR, and Semantic Scholar, among other databases, were considered for the study. The researcher included all of the articles whose scopes, areas, and variable kinds are similar and related to the phenomenon. All articles focusing on biological and epidemiological research, on the other hand, have been excluded from consideration. All of the themes that have been covered in this work are included in the section under "References."

\section{RESULTS AND DISCUSSION}

\section{HRM amidst COVID-19: Challenges and Behavioral Implications}

Human resource management is concerned with hiring, managing, and developing human resources within organizations (Anjum \& Zahan, 2021). COVID-19 has had a tremendous impact on it, providing significant challenges for managers and human resources. This section discusses the implications and challenges of HR behavioral circumstances like employee health, safety, and mental well-being; employee retention, engagement, and flexibility; employee skill and talent management; and employee productivity and motivation (Rahman et al. 2021). Each HRM topic is discussed separately; however, they are all linked up to maintain the employees. As a result, during COVID-19, any modification in one human resource management issue will influence the other.

\section{Health, Safety and Mental Well-being}

The COVID-19 pandemic has brought the employees' health issues to the front seat. During these days, employees' overall health and mental well-being have been badly affected by the world's higher level of anxiety (Dennerlein et al., 2020). The shift in work culture, fear of job security, own health issues, concern for loved ones, and isolation have negatively influenced the workers' psychological wellness (Hasteer, 2020). The COVID-19 lockdown could result in an epidemic of employees' burnouts and stress-related absenteeism in the latter days (Sanders, 2020). Thus, wellness, particularly mental health, has become a key priority for employers these days (Rice, 2021; Anjum, 2020). Today, people want organizations that truly care for them and are committed to their physical and psychological health. While physical well-being includes keeping with the trend of recent month's measures such as wearing face masks, having access to clean and sanitized office spaces, availability of equipment needed to work safely, etc. At the same time, psychological well-being includes practices that can help address employees' mental and emotional health apart from other offerings (Maqsood et al., 2021). Though health and well-being have already started an organization's overall philosophy, implementing comprehensive safety plans is also vital to keep employees feeling 
safe and supported at work (McNeill, 2021). Attention to employee morale is of utmost priority for HR professionals as the pandemic has changed the employees' perceptions and expectations toward the workplace. Effective communication is vital to recover the employees' shock and adjust them to the new way of working, therefore, empathy from management and dealing with the employee needs. The biggest challenge is that human resource needs to be monitored more consistently than ever; HR teams need to expand their involvement in employees' lives, keeping a close eye on employees' well-being (Singh, 2020).

\section{Maintenance, Engagement, and Flexibility}

The sudden shift to the work-from-home method has changed business practices and workforce preferences (Morse 2020). It is tough to maintain a systematic workflow in remote working environments, keeping employees aligned with the work objective and ensuring their engagement (Roy, 2021). Consequently, the comparative confines of home working and the risk of loneliness amidst the COVID-19 pandemic can distract employee efforts and get them disconnected from the company's purpose (Hasteer, 2020). Effective communication and coordination are compromised in a virtual setting, making it difficult to ensure transparency and address possible employee concerns (NIU, 2021). Virtual practices reduce in-person contact, resulting in less interaction, limited scope for body language, trouble expressing and chances of fraud, etc. So, HR professionals need to find common digital tools and resources to keep everyone on the same page (Singh, 2020; Sulaiman et al., 2020). They need to enhance a relationship-oriented system and maintain cohesion among these dispersed teams to keep them engaged with the work (Carnevale \& Hatak, 2020). Regular updates, meetings, and learning sessions are needed to keep the employees on track (Gaikwad, 2020). Additionally, the COVID-19 lockdown has changed the way employee manage their work and personal duties (Rahman et al. 2021). The mixture between job duties and family responsibilities has made it difficult for employees to maintain adequate work-life balance (Rahman, et al., 2021; Giurge \& Bohns, 2020). As a result, workplace flexibility is becoming a highly valued support employees are expecting during these days. HR needs to develop formal policies regarding how the employees make their work fit into their lives by taking into account the individual needs of each employee (Lefter et al., 2018). Moreover, HR needs to maintain its existing workforce to balance out again correctly. Thus, HR leaders must design better employee retention policies (Rahman et al., 2017; Nasir, 2017) and focus on succession planning.

\section{Skill and Talent Management}

The massive changes in the work environment due to redundancies, restructuring, and furlough during the COVID-19 pandemic have left organizations lacking skilled manpower. Additionally, the altered work environment demands different skills for both management and staff (Rice, 2021). Adaptability, resilience, problem-solving skills, etc., have been identified as critical roles these days (Baker, 2020; Morse 2020). Moreover, the growing remote work culture pressures recruiters to look at the digital collaboration skill of the job applicant (Singh, 2020). HR needs to modify its talent acquisition policies because remote work allows candidates to pick up positions in entirely different locations and pushes a greater workforce diversity with a broader pool of available talents (Colantuono, 2021). Shifting traditional education-based and skill-based hiring would be of paramount importance as the cost of training someone inexperienced could hinder business performance in the current situation (Hasteer, 2020). For those, who do not wish to rehire employees, an alternative has been to re-skill their existing employees. Internal mobility can create opportunities for organizations to redeploy internal employees with the right skill sets and also can help to improve the retention of top talent (Gigauri, 2020). In that case, training is 
essential to fill the skill and knowledge gap of those who took on different roles or additional responsibilities (Hite and McDonald, 2020). Thus, HR needs to develop a competency framework that defines the skills and expertise required for performing the job efficiently, which will help revitalize the workforce and lead to excellence. Rather than focusing on specific job skills, an organization's training program must focus on its employees' overall growth and career development (Nasir, 2017). Encouraging employees to develop critical skills that potentially open up multiple opportunities for their career development is also becoming an important activity of HR practitioners. Both the employers and the employees today recognize the need for agility; Employees need to up-skill, and employers need to provide workers with opportunities to learn new skills and grow (Friedman, 2021).

\section{Productivity and Motivation}

Businesses worldwide have been facing rough weather and finding it tough to survive since the outbreak of COVID-19. An employee is least productive when their job becomes insecure as they remain uncertain about the future (Sulaiman et al., 2020). Moreover, remote working makes it difficult to control and monitor employee activities. Team members become less productive, and the overall team performance lowers when the members work remotely (Van der Lippe and Lippényi, 2019). The HR professionals must have a facilitating and supporting role to improve employee performances (Parry \& Battista, 2019). To retain employee productivity, skill development and resilience should be equally prioritized within a company's strategy (Saeed et al., 2021). While coordinating hybrid work, individual performance factors such as work characteristics, satisfaction, and commitment should also be taken into account (Narayandas et al., 2020, Abdul et al., 2018). Besides, employees' wellbeing also has implications for their job outcomes. HR, thus, need to give more concern to both the physical and psychological well-being of people, especially when they are working remotely. Additionally, to face the intense market competition, companies need highly developed people with relevant knowledge who can adapt quickly to the environment, master new competencies, be receptive to innovations, and learn innovative skills. HR can plan and implement various motivational techniques for raising employee productivity (Azizi et al., 2021). It can reshape the organization's reward strategy by adding different incentive plans that are cost-effective to management. While monetary rewards such as salary hikes, bonuses, incentive programs, etc., have been preferred to appreciate people, non-monetary benefits such as flexible working hours, health care, transportation facility, etc., could also motivate the workers (Anjum et al., 2021).

This study examined core human resource management issues amidst the COVID-19 pandemic. The study addressed the first challenge as employees' health, safety, and mental well-being, which is vital for overall performance (López-Cabarcos et al., 2020; Su et al., 2021). The sudden outbreak of coronavirus disease and shift in the work culture has greatly affected employees' well-being. HR managers need to actively participate by paying close attention to employee safety regulations and addressing their level of stress, anxiety, and other psychological issues (Wu et al., 2020; Dennerlein et al., 2020). Secondly, HR managers embrace challenges in effective maintenance of employees in a remote working environment during the COVID-19 pandemic. Remote workers are isolated and less connected by nature (Rahman et al., 2021). It is not easy to administer the HR following the traditional way in this situation. Therefore, HR professionals recommend effective communication mechanisms for engaging these workers (Gaikwad, 2020). HR also needs to ensure greater employee flexibility and must engage them in the issues related to new work policies. Employees need flexibility in terms of working hours, rest periods, leave facilities, and even role or task distribution, especially in the case of remote work arrangements (Peasley et al., 2020). Thirdly, HR professionals must take responsibility to face the challenge of employee 
retention by upgrading their skills and abilities at this pandemic time (Parry and Battista, 2019). Additionally, HR professionals must apply creative talent management methods to ensure their career growth and survival in the organization (Gigauri, 2020). In this situation, establishing employee performance evaluations for a remote working context is also necessary (Baker, 2020). Finally, ensuring employee productivity and keeping them motivated in COVID-19 new normal must be in the front seat for HR professionals. HR practitioners need to respond to this challenge through higher transparency, effective monitoring, addressing employee needs and maintaining healthy relationships (Singer-Velush et al., 2020; Dash Mohapatra, 2020; Sanders, 2020). Since the COVID-19 pandemic created a challenging environment for human resource management, the issues presented in this study could be a good source for HR practitioners to respond to the crisis, revive organizational operations and ensure effective manpower management.

\section{Implications of the Study}

The word crisis is unavoidable in the world of business. The new crisis inflicted by COVID19 turns traditional approaches to encounter many problems for managers and HR practitioners who lacked the requisite knowledge, skills and abilities to deal with the unforeseen event. Not only that, it gives tremendous opportunity to the HR practitioners to utilize HR effectively and efficiently. This study is a thorough literature analysis that provides key issues for managers and HRM practitioners to grasp a better idea about the challenges and implications associated with COVID-19 to run the organization. The insights into future manpower management directions provided in this paper should help them build an intervention plan specific to their companies and people's requirements.

\section{CONCLUSION}

The main goal of any organization in the current COVID-19 situation is to survive, ensure the safety of employees, and maintain effective management of human resources. Employers need to keep in touch with the workforce and their lives more closely during this crisis. The HR professionals have a facilitating and supporting role in this transformation. The COVID19 pandemic has made it visible for HR professionals to gain more knowledge in manpower management issues. While outlining the human resource challenges amidst the COVID-19 crisis, this study suggested that some HR practitioners ensure employee health and wellbeing, welfare, productivity, motivation, engagement, adaptation to change, skill and talent management, career growth retention, flexibility, etc. Therefore, the study has significant behavioral implications for HR practitioners and is worth empirical study on manpower management in the pandemic scenario. However, further studies are recommended on the short or long-term impact of COVID-19 on human resources or the post-pandemic human resource challenges based on the survey. Quantitative research methods can also be applied to a specific group of people to understand their perceptions about this contemporary issue.

\section{Potential conflict of interest}

The authors state that there were no commercial or financial relationships that may have been considered a potential conflict of interest during the research.

\section{Funding Information}

The authors did not receive any fund. 


\section{REFERENCES}

Al-ahdal, W. M., Alsamhi, M. H., Tabash, M. I., \& Farhan, N. H. (2020). The impact of corporate governance on financial performance of Indian and GCC listed firms: An empirical investigation. Research in International Business and Finance, 51, 101083. https://doi.org/10.1016/j.ribaf.2019.101083

Anjum N. (2020). COVID-19 Pandemic: How does social media affect psychological wellbeing? - A synthesis of literature review. International Journal of Indian Psychology, 8(3), 1698-1707. https://doi.org/10.25215/0803.173

Anjum, N., Islam, M. A., Choudhury, M. I., \& Saha, J. (2021). Do Intrinsic Rewards Matter on Motivation? Evidence from Primary School Teachers of Bangladesh. SEISENSE Journal of Management, 4(1), 47-58. https://doi.org/10.33215/sjom.v4i1.534

Anjum, N., \& Islam, M. A. (2020). Employees' Behavioral Intention to Adopt E-HRM SystemAn Approach to Extend Technology Acceptance Model. International Journal of Academic Research in Accounting Finance and Management Sciences, 10(3), 544-561. http://dx.doi.org/10.6007/IJARAFMS/v10-i3/8140

Azizi, M. R., Atlasi, R., Ziapour, A., Abbas, J., \& Naemi, R. (2021). Innovative human resource management strategies during the COVID-19 pandemic: A systematic narrative review approach. Heliyon, e07233. https://doi.org/10.1016/j.heliyon.2021.e07233

Carnevale, J. B., \& Hatak, I. (2020). Employee adjustment and well-being in the era of COVID-19: Implications for human resource management. Journal of Business Research, 116, 183-187. https://doi.org/10.1016/j.jbusres.2020.05.037

Dash Mohapatra, B. (2020). Managing manpower amid and post pandemic in India. An evocative study Bighnesh Dash Mohapatra, 2, 1-8. International Journal of Research in Human Resource Management, 2(1): 18-25. https://doi.org/10.1016/j.jbusres.2020.05.037

Davidescu, A. A., Apostu, S. A., Paul, A., \&Casuneanu, I. (2020). Work flexibility, job satisfaction, and job performance among Romanian employees-Implications for sustainable human resource management. Sustainability, 12(15), https://doi.org/10.3390/su12156086

Ghewari, A., Pawar, S., \& Jadhav, T. (2021). Challenges to hr professionals due to covid-19 pandemic. International Journal of Management (IJM), 12(3). https://doi.org/10.34218/IJM.12.3.2021.027

Gigauri, I. (2020). Challenges HR Managers Facing due to COVID-19 and Overcoming Strategies: Perspectives from Georgia.Archives of Business Review-8(11). https://doi.org/10.14738/abr.811.9313

Gigauri, I. (2020). Influence of Covid-19 Crisis on Human Resource Management and Companiesâ€ $€^{\mathrm{TM}}$ Response: The Expert Study. International Journal of Management Science and Business Administration, 6(6), 15-24. https://doi.org/10.18775/ijmsba.1849-5664-5419.2014.66.1002

Giurge, L. M. \& Bohns, V. K. (2020, April 3). 3 Tips to Avoid WFH Burnout. Retrieved on 25 June, 2021 from Harvard Business Review. Available at: https://hbr.org/2020/04/3-tips-to-avoid-wfh-burnout

Hasteer, R. (2020, October 17). Expected Challenges for HR Professionals in Startups. Retrieved on 13 June, 2021 from inc42. Available at: 
https://inc42.com/resources/expected-challenges-for-hr-professionals-in-startuppost-covid/

Hite, L. M., \& McDonald, K. S. (2020). Careers after COVID-19: Challenges and changes. Human Resource Development International, 23(4), 427-437. https://doi.org/10.1080/13678868.2020.1779576

Dennerlein, J. T., Burke, L., Sabbath, E. L., Williams, J. A., Peters, S. E., Wallace, L., ... \& Sorensen, G. (2020). An integrative total worker health framework for keeping workers safe and healthy during the COVID-19 pandemic. Human factors, 62(5), 689-696. https://doi.org/10.1177/0018720820932699

Lefter, V., Davidescu, A. A., \& Casuneanu, I. (2018). Identifying the Main Factors of Workplace Flexibility Among Romanian Employees. In Solutions for Business, Culture and Religion in Eastern Europe and Beyond (pp. 115-128). Springer, Cham.

López-Cabarcos, M., López-Carballeira, A., \& Ferro-Soto, C. (2020). New ways of working and public healthcare professionals' well-being: The response to face the covid-19 pandemic. Sustainability, 12(19), 8087. https://doi.org/10.3390/su12198087

Maqsood, A., Abbas, J., Rehman, G., \& Mubeen, R. (2021). The paradigm shift for educational system continuance in the advent of COVID-19 pandemic: Mental health challenges and reflections. Current Research in Behavioral Sciences, 2, https://doi.org/10.1016/j.crbeha.2020.100011

McNeill, M. (2021, March 18). 3 Challenges of HR Post-COVID. Retrieved on 12 June, 2021 from ICS learn. Available at: https://www.icslearn.co.uk/blog/posts/2021/march/3challenges-of-hr-post-covid/

Morse, L. (2020, July 28). Addressing Post-COVID HR Issues. Retrieved on 12 June, 2021 from Human Capital- a vensure employer services company. Available at: https://www.human-capital.com/michigan-hr-services/blogs/addressing-post-covidhr-issues/

Nangia, M., \& Mohsin, F. A. R. H. A. T. (2020). Revisiting talent management practices in a pandemic driven VUCA environment-a qualitative investigation in the Indian IT industry. Journal of Critical Reviews, 7(7), 937-942. https://doi.org/10.31838/jcr.07.07.170

Narayandas, D., Hebbar, V., \&Liangliang, L. (2020, June 5). Lessons from Chinese Companies' Response to Covid-19. Retrieved July 28, 2020, from Harvard Business Review: https://hbr.org/2020/06/lessons-from-chinese-companies-response-to-covid$\underline{19}$

Nasir, S. Z. (2017). Emerging challenges of HRM in 21st century: A theoretical analysis. International Journal of Academic Research in Business and Social Sciences, 7(3), 216-223. http://dx.doi.org/10.6007/IJARBSS/v7-i3/2727

NishaChanana, S. (2020) Employee engagement practices during COVID-19 lockdown. Journal of Public Affairs. 21:e2508. https://doi.org/10.1002/pa.25088

Parry, E., \& Battista, V. (2019). The impact of emerging technologies on work: a review of the evidence and implications for the human resource function. Emerald Open Research, 1, 5. https://doi.org/10.12688/emeraldopenres.12907.1

Singh, P. K., Kiran, R., Bhatt, R. K., Tabash, M. I., Pandey, A. K., \& Chouhan, A. (2021). COVID-19 pandemic and transmission factors: An empirical investigation of 
different countries. Journal of Public Affairs, 21(4), e2648. https://doi.org/10.1002/pa.2648

Peasley, M. C., Hochstein, B., Britton, B. P., Srivastava, R. V., \& Stewart, G. T. (2020). Can't leave it at home? The effects of personal stress on burnout and T salesperson performance. Journal of Business Research (117), 58-70. https://doi.org/10.1016/j.jbusres.2020.05.014

Rahman, M. M., Uddin, M. J., \& Rahaman, S. (2019), "Work-family, family-work conflict and subjective well?being of commercial bank employees in Bangladesh: The moderating effects of organisational supports", Advances in Management and Applied Economics, 9(6), 77-96. https://doi.org/10.29121/granthaalayah.v8.19.2020.1120

Rahaman, M. S., Rahman, M. M., \& Moral, I. H. (2020). Informative knowledge and challenges of home quarantine during COVID-19 in Bangladesh. International Journal of Technology Transfer and Commercialisation, 17(4), 354-367. https://doi.org/10.1504/IJTTC.2020.113212

Rahman, M. M., \& Ali, N. A. (2021). Does work-family balance mediate the relationship between work-family conflicts and job satisfaction of academicians? Journal of Community Psychology, 49(2), 361-374. https://doi.org/10.1002/jcop.22464

Rahman, M.M., Ali, N.A., Jantan, A.H., Mansor, Z.D. \& Rahaman, M.S. (2020). Work to family, family to work conflicts and work family balance as predictors of job satisfaction of Malaysian academic community, Journal of Enterprising Communities: People and Places in the Global Economy, 14(4), 621-642. https://doi.org/10.1108/JEC-05-2020-0098

Rahman M. M, Uddin M. B. Chowdhury M. S, Rahaman M. S. (2021) Psychological Status of Private Commercial Bank Employees in Bangladesh during COVID-19. Journal of Business Strategy Finance and Management, 3(1,2). http://dx.doi.org/10.12944/JBSFM.03.01-02.07

Rahaman, M. S., Rahman, M. M., Ali Reza, S. M., Reza, M. N., \& Chowdhury, M. S. (2021). Thank you, COVID-19: Positive social psychology towards the new normal. Journal of Public Affairs, e2766. https://doi.org/10.1002/pa.2766

Rahman, M. M., \& Rahaman, M. S. (2021). Psychological status of mass people in the capital city of Bangladesh during COVID-19: Do home quarantine challenges matter?. Journal of Community Psychology. https://doi.org/10.1002/jcop.22756

Abdul, M. O. H. A. N. I., Rahman, M. M., ALIa, N. A., Dato'Mansor, Z. U. R. A. I. N. A., Uddin, M. J., \& Saidur, M. (2018). The Nexus between job satisfactions and human resource management (HRM) practices: A perceptual analysis of commercial banks in Bangladesh. International Journal of Economics and Management, 12(S2), 377386. https://doi.org/10.14419/ijet.v8i1.9.26700

Rice, D. (2021, May 19). The 6 Biggest Challenges HR Faces in a Post COVID World. Retrieved on 14 June, 2021 from HR Exchange Network- keeping HR professionals at the forefront of industry change. Available at: https://www.hrexchangenetwork.com/hr-talent-management/articles/the-6-biggestchallenges-hr-faces-in-a-post-covid-world

Risley, C. (2020). Maintaining performance and employee engagement during the COVID-19 pandemic. Journal of Library Administration, 60(6), 653-659. https://doi.org/10.1080/01930826.2020.1773716 
Roy, B. D. (2021, May 5).Challenges of HR and Its Shift Post COVID-19 Pandemic. Retrieved on 11 June, 2021 from VANTAGE CIRCLE Blog. Available at: https://blog.vantagecircle.com/challenges-of-hr/

Saeed, A., Rasheed, F., Waseem, M. and Tabash, M.I. (2021), "Green human resource management and environmental performance: the role of green supply chain management practices", Benchmarking: An International Journal, Vol. ahead-ofprint No. ahead-of-print. https://doi.org/10.1108/BIJ-05-2021-0297

Sulaiman, M. A. B. A., Ahmed, M. N., \&Shabbir, M. S. (2020). Covid-19 challenges and human resource management in organized retail operations. Utopia y Praxis Latinoamericana, 25(12), 81-92. http://doi.org/10.5281/zenodo.4280092

Su, Z., McDonnell, D., Wen, J., Kozak, M., Abbas, J., Šegalo, S., ...\& Xiang, Y. T. (2021). Mental health consequences of COVID-19 media coverage: the need for effective crisis communication practices. Globalization and health, 17(1), 1-8. https://doi.org/10.1186/s12992-020-00654-4

Farooq, U., Tabash, M. I., Anagreh, S., \& Alnahhal, M. (2021). Assessing the impact of COVID-19 on corporate investment behavior. Emerging Science Journal, 5(1),130140. https://doi.org/10.28991/esj-2021-SPER-11

Van der Lippe, T., \&Lippényi, Z. (2019). Co-workers working from home and individual and team performance. New Technology, Work and Employment, 35(1), 60-79. https://doi.org/10.1111/ntwe.12153

Wu, L. K., Su, W. H., Hsiao, S. H., \&Hou, M. F. (2020). Preparedness for the next emerging infectious disease outbreak by implementing strategic human resource management. Journal of the Chinese Medical Association, 83(10), 973. https://doi.org/10.1097/JCMA.0000000000000423

YoosefiLebni, J., Abbas, J., Moradi, F., Salahshoor, M. R., Chaboksavar, F., Irandoost, S. F., ...\& Ziapour, A. (2021). How the COVID-19 pandemic effected economic, social, political, and cultural factors: A lesson from Iran. International Journal of Social Psychiatry, 67(3), 298-300. https://doi.org/10.1177/0020764020939984 